\title{
Smart load cells: an industrial application
}

\author{
J.G. Rocha* , C. Couto, J.H. Correia \\ Department of Industrial Electronics, University of Minho, Campus de Azurem, 4800 Guimaraes, Portugal \\ Received 14 September 1999; received in revised form 8 February 2000; accepted 9 February 2000
}

\begin{abstract}
This paper presents a data acquisition solution using a RISC type microcontroller with very few components around, taking advantage of the ratiometric functioning of the load cells. The need of thermally stable circuits is minimized through the use of the same amplification chain for both signal and reference. The amplification and filtering are done trough switched-capacitor techniques controlled by the microcontroller. This option allows the choice of the proper scale according to the platform and permits the autocalibration of the system. The weighing tests show errors below $100 \mathrm{~g}$ in $400 \mathrm{~kg}$ for an industrial platform of eight smart load cells. The paper also describes an example of software calibration of a multiload cell weigh-bridge using one processor per smart load cell. (C) 2000 Elsevier Science S.A. All rights reserved.
\end{abstract}

Keywords: Load cell interfaces; Industrial weighing systems; Smart sensors

\section{Introduction}

Load cells are force sensors which are used in industrial weighing equipment. Multiload-cell weighing systems usually use a single signal processing circuit associated with the individual load cell outputs tied together (electrical paralleling). Because of this electrical paralleling, the tuning of the gain of each load cell affects the behavior of the others, calibration is difficult and tedious, specially with weigh-bridges for cars and trucks, requiring the motion of heavy reference weights around large platforms (Fig. 1) [1].

The use of load cells with digital output, i.e., with integrated signal processing allows the gain adjustment to be a simple multiplication of the load cell output by a coefficient, an operation which does not affect the other load cell outputs (Fig. 2). In this case, the calibration process means the calculation of the multiplying coefficients, which are given by the solution of a set of equations, an operation easily performed by any generalpurpose microcomputer. However, this solution needs a cost-effective signal processing circuit including amplifica- tion, analog to digital conversion and networking capabilities [2].

For industrial weighing applications 6000 divisions are needed for the equipment (external divisions), a conversion resolution of at least 60000 divisions (10 internal divisions for each external). For static weighing applications, 50 or more readings per second are needed. For dynamic weighing a faster reading rate may be required but normally with lower resolution.

\section{Design strategy}

In this system based on switched-capacitor circuits (SCs), three discrete differential signals are obtained from a transducer bridge: the zero signal $\left(V_{\text {zero }}\right)$, the signal from the load cell $\left(V_{\text {in }}\right)$ and the reference $\operatorname{signal}\left(V_{\text {ref }}\right)$ (Fig. 3). The noninverting inputs of $\mathrm{A} 1$ and $\mathrm{A} 2$ amplifiers are properly switched to deal with the zero, the load cell signal and the reference. Each one of the previous three signals is added with an extra one $\left(V_{\text {offset }}\right)$, also obtained from the

\footnotetext{
* Corresponding author. Tel.: +351-253-510190; fax: +351-253510189 .

E-mail address: gerardo@dei.uminho.pt (J.G. Rocha).
}

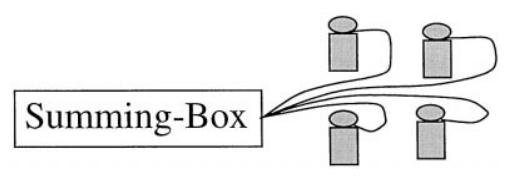

Fig. 1. Classical solution in a multiload cell weighing system. 


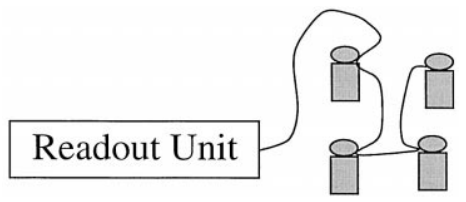

Fig. 2. Modern solution in a multiload cell weighing system: no summing box, single cable, load cells with digital output and software calibration possibility.

transducer bridge, using the summing amplifier A5, so that, $V_{\text {zero }}, V_{\text {in }}$ and $V_{\text {ref }}$ are affected by the same offset voltage. As the same amplifier chain is switched between the zero, the load cell signal and the conversion reference, the thermal stability requirements for the amplifier can be relaxed as a change in its gain or input offset voltage $\left(V_{\mathrm{os}}\right)$ will affect all the three entities during the A-D conversion. A simple architecture is just enough to ensure that the amplifier gain and $V_{\text {os }}$ remain constant during the conversion period.

The A5 output is filtered and inverted by a low pass SC filter and buffered by A6. The SC filter is necessary for several reasons: (1) it is necessary to eliminate the highfrequency noise produced in the amplifier stage by the commutation of the SCs; (2) the filter cut-off frequency must be programmable, once the the A-D input signal must be very stable at the conversion instants. This means that the cut-off frequency must be low. On the other hand, when the amplifier input is commuted from $V_{\text {zero }}$ to $V_{\text {in }}$ and from $V_{\text {in }}$ to $V_{\text {ref }}$ (time gaps $T_{1}$ and $T_{2}$, Fig. 4), the filter output signal must adapt itself to the new signal very quickly and consequently it needs a high cut-off frequency.
The A-D conversion is based on the single-ramp technique where the circuit around A7 amplifier forms a ramp generator. At the A8 input summing point, the current due to the ramp is subtracted from the current proportional to the signal. When this current difference is large, A8 operates at a low gain due to the diodes in the feedback loop. When the current produced by the ramp potential and A6 output's current are very nearly balanced, the potential at A8 summing junction will go low enough, so that A8's signal comes out of the diode bounding and operates with a gain determined by the feedback resistor $(390 \mathrm{k} \Omega$ ). Amplifier A8 makes the comparator's job much easier; it amplifies the voltage difference of the two signals to be compared by a factor of 100 , reducing the comparator input uncertainties. The comparator components in the positive feedback path ensure a sharp transition.

Normally, to do the conversions of the zero, the load-cell signal and the reference, three ramps are necessary, one for each value. In this case, to minimize the hardware and reduce the errors, the same comparator is used to detect the three level crossings [3], reducing the average conversion time to one third. One problem is to allow enough time to switch the amplifier chain from one signal to the other, until there is a stable output. This was accomplished in the conversion by restricting $\left(V_{\mathrm{in}_{\min }}-V_{\text {zero }}\right)$ and $\left(V_{\text {ref }}-V_{\mathrm{in}_{\max }}\right)$ to be greater than a minimum voltage to allow the transients to settle (Fig. 4). This strategy reduces the $V_{\text {in }}$ range but the precision of the conversion is improved.

All the circuit is developed around an eight-bit singlechip Harvard architecture microcontroller with RISC-like features and operating speed of $250 \mathrm{~ns}$ for each instruction

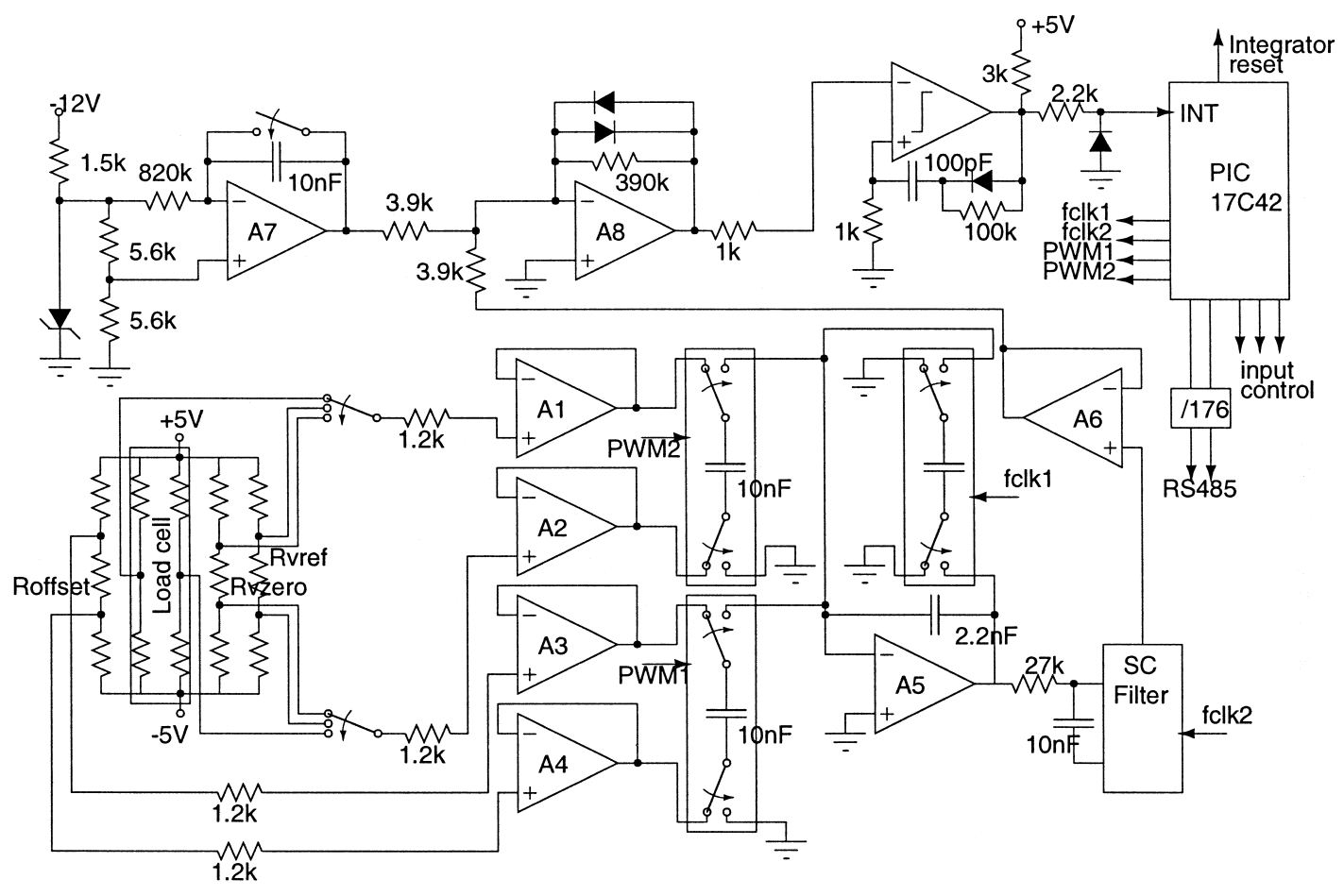

Fig. 3. The smart load cell signal processing circuit. 


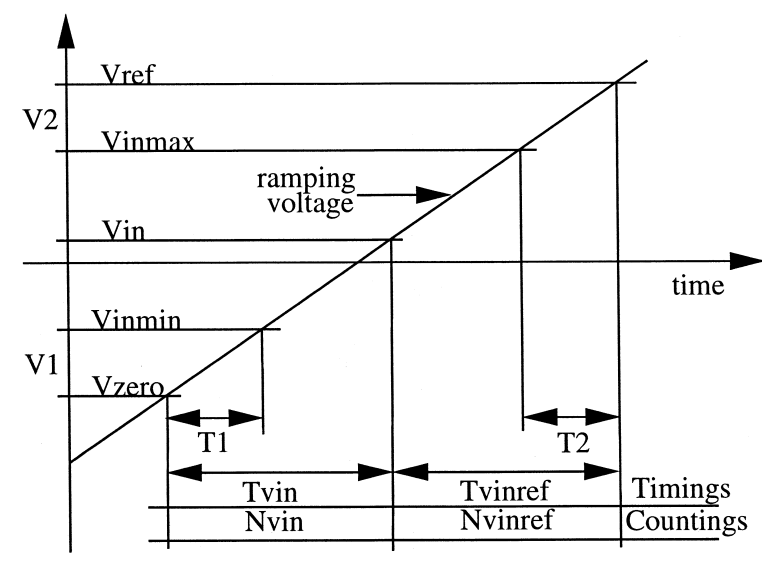

Fig. 4. The single-ramp conversion scheme implemented.

cycle with $16 \mathrm{MHz}$ of clock input. The counting associated with the single ramp A-D conversion, the control of the switches in the amplifier stage and the ramping capacitor discharge are tasks performed by the microcontroller. Other tasks of the microcontroller are related with the conversion result, which may include scaling, eventually some digital filtering and the communications with the outside world.

The final value of the load cell output is obtained by microcontroller, from the three converted values by means of the three-signal technique [4]. The application of this technique in the present work requires the measurement of $V_{\text {zero }}, V_{\text {in }}$ and $V_{\text {ref }}$. These three measurements result in three output signals $N_{\text {zero }}, N_{\text {in }}$ and $N_{\text {ref }}$, all of them affected by the same offset and gain error. The final conversion result can be obtained from the following calculation:

$W=\frac{N_{\text {in }}-N_{\text {zero }}}{N_{\text {ref }}-N_{\text {zero }}} \times W_{\text {max }}$

where $W_{\max }$ is the full-scale weight of the load cell, which is equal to $100 \mathrm{~kg}$ in the pesent work.

\section{Digital filtering}

Besides the analog filtering implemented with SC, a digital filter is applied taking advantage of the microcontroller. As it is well known, after a mass be placed on the weighing platform and its output be stabilized, it is natural that exists a little variation on the A-D output due to its high resolution. This is not very practical when the final result is shown on a display, where a constant value must appear. Therefore, the digital filter must have a fast response when the mass on the platform is changed and a very smooth response when the mass is constant. An adaptative filter is once again required to achieve both, a rapid response and a smooth output.
Expression 1 shows the scheme of a possible self-adaptative digital filter:

$y(n)=y(n-1)+\frac{u(n)-y(n-1)}{N}$

where $y(n)$ is the value to sample; $u(n)$, value from the $n$th conversion; $y(n-1)$ last value sampled; $N$ filtering constant.

For $N=1, y(n)=u(n)$. With increasing $N$ the influence of the last reading in the value to sample is less. The filter response is fast for low values of $N$ but the output takes much time to settle (small oscillations). For high values of $N$ the filter response is slow until the settling of the output occurs.

An error integral, $D(k)$ is defined as:

$D(k)=\sum_{k=1}^{n} u(k)-y(k-1)$

which represents the sum of the differences between the last value sampled and the reading. The error integral regulates the number of readings to take into consideration and the filtering constant to choose.

The error integral is compared with a constant parameter designated STACK, which represents the maximum variation of the output before a transition happens. When the conversions are randomly spread around the result shown, the integral error fluctuates around zero and the $N$ parameter must be high $(8,16,32$ or more). When there is a change in the weight, $D(k)$ grows steadily and after a few conversions exceeds the threshold level STACK. The error integral is restarted to zero and $N$ is set to a low value $(1,2,4, \ldots)$.

Normally the value of $N$ must be a power of 2 to make the filtering algorithm simpler and faster, as the division by $N$ can be implemented by a simple binary shift [5].

The use of smart load cells with digital outputs needs a cost effective digital filtering of the final results for each smart load cell. The presence of the microcontroller per smart load cell allows the use of this self-adaptative pseudo-moving average filter (software solution) to achieve a stable digital output with a fast response to weight changes. The technique is established by theoretical analysis and is justified by means of simulation and experimental results.

\section{Software calibration}

The calibration process means the calculation of the multiplying coefficients, which are given by the solution of a set of equations, operation easily performed by any general-purpose microcomputer.

For $N$ load cells platform, $N$ sets of $N$ readings were made and the weights found were used to work out the multiplying coefficients $\left(K_{i}\right)$. These factors that affect 
each one of the readings enables the correct evaluation of the weight above the platform. A system of $N$ equations and $N$ unknowns was built:

$$
\left\{\begin{array}{l}
K_{1} W_{11}+K_{2} W_{12}+\cdots+K_{N} W_{1 N}=W_{\text {calib }} \\
K_{1} W_{21}+K_{2} W_{22}+\cdots+K_{N} W_{2 N}=W_{\text {calib }} \\
K_{1} W_{31}+K_{2} W_{32}+\cdots+K_{N} W_{3 N}=W_{\text {calib }} \\
\vdots \\
K_{1} W_{N 1}+K_{2} W_{N 2}+\cdots+K_{N} W_{N N}=W_{\text {calib }}
\end{array}\right.
$$

where $W_{i j}$ is the output of the load cell $j$ in loading situation $i$ and $W_{\text {calib }}$ is the weight of the calibration mass.

The solution of this system gives the $K_{i}$ factors required to evaluate an unknown weight.

After calibration the resolution of Eq. (2) determines the weight of the mass on the platform (with $W_{i}$ the output of each smart load cell).

Mass $=K_{1} \times W_{1}+K_{2} \times W_{2}+\cdots+K_{N} \times W_{N}$

\section{Experimental results}

Fig. 5 shows an example of the A-D converter working principle for a given $V_{\text {in }}$ and $V_{\text {ref }}=5.1 \mathrm{~V}$. The waveform Ch1 is the amplifier output, illustrating the input signal switchings and Ch2 waveform is the ramp generator output.

The software calibration method is tested with two four-load cell platforms (Fig. 6) and eight digital readout units with networking facilities. Load cells taking a maximum nominal weight of $100 \mathrm{~kg}$, with 3000 divisions of resolution and a sensitivity around $2 \mathrm{mV} / \mathrm{V}$ are used. Each of the readout units are calibrated to give around $60 \mathrm{~kg}$ with a $20-\mathrm{g}$ resolution. Two sets of tests were done: one

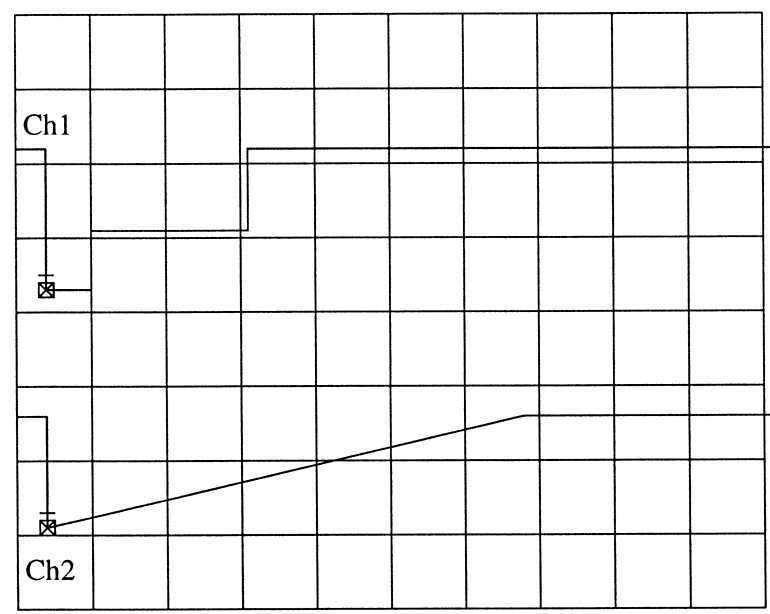

Fig. 5. Screen plot of A6 and A7 outputs respectively. Ch1 at 5 $\mathrm{V} /$ division; Ch2 at $5 \mathrm{~V} /$ division, time base at $2 \mathrm{~ms} /$ division for a load of $200 \mathrm{~kg}$.

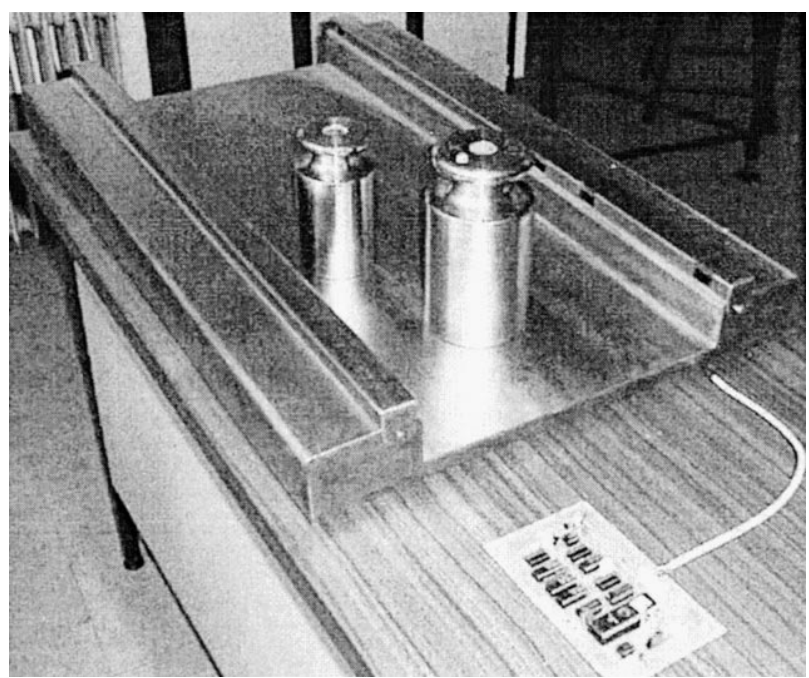

Fig. 6. Complete weighing system of four smart load cells.

for a four-load cell platform and another for an eight-load cell system.

$N$ readings of weight on each load cell are obtained by moving a known mass around the platform. The best results are achieved concentrating the weight of the mass as much as possible above each one of the load cells.

The following $W_{r c}$ readings are measured (in $\mathrm{kg}$ ) with a calibrated mass of $20 \mathrm{~kg}$ positioned in four different positions:

$\left\{\begin{array}{lcccc}W_{1 \mathrm{c}} \rightarrow & 3.86 & 9.96 & 6.82 & 0.72 \\ W_{2 \mathrm{c}} \rightarrow & 1.74 & 2.94 & 10.88 & 5.58 \\ W_{3 \mathrm{c}} \rightarrow & 4.50 & 0.74 & 3.54 & 13.26 \\ W_{4 \mathrm{c}} \rightarrow & 13.30 & 2.92 & 1.48 & 4.38\end{array}\right.$

and the resulting $K$ factors were:

$K_{1}=0.90025 \quad K_{2}=0.91580 \quad K_{3}=0.99196$

$K_{4}=0.88685$

Using the $K$ factors calculated above, several weighing operations are done with different masses, located in different points on the platform. Very encouraging results

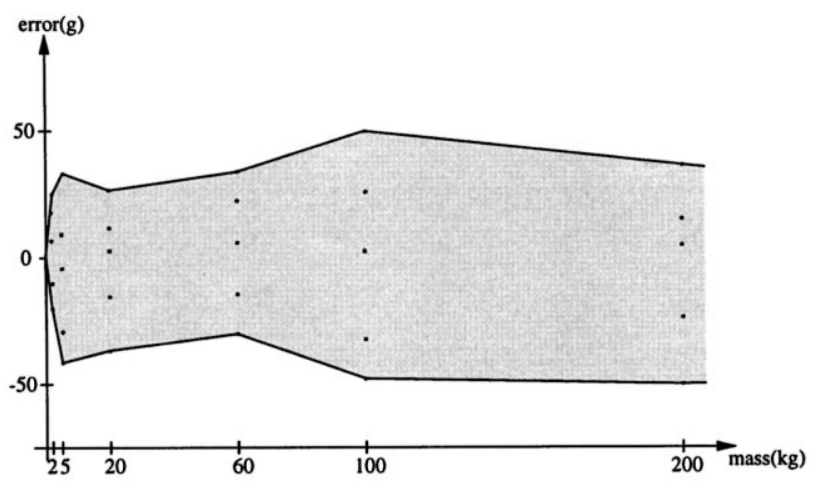

Fig. 7. Deviation of the weighing results for a four-load-cells platform. 
have been read, with errors below $50 \mathrm{~g}$ (4000 divisions in $200 \mathrm{~kg}$ ). Some of the measured errors are shown in Fig. 7.

For the composite platform with eight load cells the test is repeated and the eight multiplying coefficients are calculated. The weighing tests confirmed the approach used giving errors below $100 \mathrm{~g}$, i.e., 4000 divisions in $400 \mathrm{~kg}$.

\section{Conclusions}

This architecture was shown to give the required performance at very reasonable cost. The implementation of smart cells including self-calibration and networking facilities seems achievable and cost effective even for multiload-cell applications, where considerable reductions on the commissioning time, through the software system calibration is highly interesting.

The results achieved so far were very encouraging regarding static or quasi-static weighing applications. Now, we are already working on the new filtering algorithms having in mind dynamic weighing. In dynamic weighing systems conventional filtering methods employed have limitations for improving accuracy and throughput rate. The Kalman filter probably provides an effective alternative to the conventional method especially when the system is nonlinear and low frequency noise is incorporated in the bandwidth of the useful signal.

Moreover, silicon does not suffer from hysteresis or creep (like conventional steel load cells) and therefore it is an ideal material for fabricating load cells [6]. To merge each load cell with the respective signal processing circuit, full process compatible [7], will create a new generation of load cells.

\section{Acknowledgements}

We wish to thank CEL-Cachapuz Electrónica, an electronic weighing equipment manufacturer, for promptly making available to us the platforms and the readout units used in this work.

\section{References}

[1] J.H. Huijsing, Integrated smart sensors, Sens. Actuators, A 30 (1992) $167-174$.

[2] C. Couto, J.H. Correia, Intelligent signal processing for ratiometric data acquisition: a low cost solution for load cells, Proceedings of IMEKO TC-4, Brussels, Belgium, 1993.

[3] C. Couto, J.H. Correia, Smart load cells based on switched-capacitors, Proceedings of ICSPAT'94, Dallas, USA, 1994.

[4] G.C.M. Meijer, J. van Drecht, P.C. de Jong, H. Neuteboom, New concepts of smart signal processors and their application to PSD displacement transducers, Sens. Actuators, A 35 (1992) 23-30.

[5] J.H. Correia, C. Couto, Digital filtering in smart load cells, Proc. of IEEE IECON'95, FL, USA, 1995, pp. 990-994.

[6] R. Wiegerink, R. Zwijze, G. Krijnen, T. Lammerink, M. Elwenspoek, Quasi monolithic silicon load cell for loads up to $1000 \mathrm{~kg}$ with insensitivity to non-homogeneous load distributions, Proc. of MEMS'99, FL, USA, 1999, pp. 558-563.

[7] J.H. Correia, E. Cretu, M. Bartek, R.F. Wolffenbuttel, A microinstrumentation system for industrial applications, Proc. of IEEE International Symposium on Industrial Electronics (ISIE'97), Guimarães, Portugal, July 7-11, 1997, pp. 846-850.

\section{Biographies}

José Gerardo V. Rocha graduated in Industrial Electronics Engineering in 1995 and obtained his MSc degree in 1999, both titles at the University of Minho, Portugal. Since 1996, he has been a lecturer in the Department of Industrial Electronics, University of Minho, Portugal and he is involved in the research of radiation sensors.

Carlos A.C.M. Couto graduated in electrical engineering at University of Lourenço Marques, Mozambique in 1972. He obtained the MSc degree in 1979 and $\mathrm{PhD}$ degree in 1981 at UMIST (University of Manchester Institute of Science and Technology), UK, both in power electronics. In 1976, he joined the University of Minho in Portugal, where since 1995, he has been full professor in the Department of Industrial Electronics. His research interests are microsystems, instrumentation and power electronics.

José Higino Correia graduated in physical engineering at University of Coimbra, Portugal in 1990. He obtained his PAPCC (equivalent to MSc degree) in 1994 at University of Minho, Portugal and his PhD degree in 1999 at Delft University of Technology, the Netherlands. His thesis work dealt with the development of optical microsystems in silicon for the visible part of the spectrum. Since May 1999, he has been an assistant professor in the Department of Industrial Electronics at University of Minho and he is involved in instrumentation and measurement in general and on-chip functional integration of microelectronic circuits and silicon sensors. 